\title{
La pragmática masculina del control: del gobierno de sí mismo hacia la violencia contra las mujeres
}

\author{
Iván Sambade ${ }^{1}$
}

\begin{abstract}
SÍNTESIS
En las modernas sociedades occidentales, la masculinidad hegemónica parece haberse concretado en el mito del varón autosuficiente que compite en el mercado laboral por dinero, éxito y prestigio. En cambio, el resto de creencias de la mística de la masculinidad como la belicosidad esencial de los varones o su supremacía respecto de las mujeres perdura latente en el imaginario colectivo de nuestras sociedades. La lacra social de la violencia de género pone de manifiesto que los varones occidentales siguen siendo socializados en los mitos de la masculinidad hegemónica. De este modo, los varones somos educados en un conjunto de prácticas de autocontrol mediante las cuales interiorizamos el recurso de la violencia como forma de dominación de las mujeres. Este conjunto de prácticas masculinas constituye la "pragmática del control".
\end{abstract}

\begin{abstract}
Apparently, in modern Western societies, the hegemonic masculinity has resulted in the myth of the self-sufficient man which competes in market economy for success and prestige. However, the mystic of masculinity endures latent in the imaginary of our societies. The representation of masculinity remains as natural violence and as superiority towards women. The social scourge of gender violence shows that Western men are still socialized into hegemonic masculinity. Thus, men are educated in a group of practices of self-control by which the use of violence is internalized as a form of domination of women. This group of masculine practices is the "pragmatics of control".
\end{abstract}

Palabras clave: Occidente - masculinidad - violencia - control.

Key words: Western - masculinity - violence - control.

\section{Masculinidad y violencia en las sociedades occidentales}

En el seno de la sociología, existe absoluta unanimidad en que "en todo el mundo, desarrollado o en vías de desarrollo, la 
conducta antisocial es esencialmente masculina. La violencia, la agresión sexual a los niños, el consumo de drogas ilegales, el abuso de alcohol, el juego, todas son actividades abrumadoramente masculinas." (Clare, 2002, 12).

La violencia de género, en tanto que forma específica de violencia masculina, constituye una lacra social de primera magnitud en el mundo actual. En Viena, en 1993, Naciones Unidas señaló que la violencia contra las mujeres es el crimen contra la humanidad más extendido, tolerado e impune. Existe en cualquier país del mundo bajo diversos grados de complicidad social. Pero esta problemática presenta su realidad más paradójica en las sociedades occidentales. Pues, habiendo asumido los varones los principios democráticos que las sustentan, se muestran incapaces de erradicar de sus conductas las prácticas de discriminación y dominación de las mujeres que perpetúan la desigualdad social entre los sexos.

Algunos investigadores han visto en el claro protagonismo de la violencia por parte de los varones y el exponencial incremento del suicidio masculino en los países europeos durante los últimos treinta años un profundo malestar indicativo de una crisis identitaria (Clare, 2002). Las causas de este malestar se encontrarían en la pérdida de control del colectivo masculino de aquellos espacios donde tradicionalmente los varones adquirían su identidad. Es decir, en la progresiva ocupación del espacio público por parte de las mujeres y su consecuente emancipación social y económica (Badinter, 1993). Aunque, por otro lado, si los varones siguen desarrollando ciertas prácticas de discriminación y dominación de las mujeres es porque sigue existiendo una situación estructural de desigualdad que perpetúa su mayor acceso al poder y sus privilegios sociales, a pesar de la fragmentación de la cosmología androcéntrica y falonarcisista (Bourdieu, 2005).

La idea que pretendo aportar a esta investigación es que si los varones ejercen violencia como consecuencia de una crisis identitaria que se produce frente a la pérdida del control sobre los dominados, fundamentalmente sobre las mujeres, es porque su autoestima y su estabilidad emocional se origina en su socialización a partir de un conjunto integrado por practicas de autocontrol y por los discursos legitimadores de dichas prácticas que he denominado la "pragmática del control". El análisis 
genealógico de la pragmática del control pondrá de manifiesto que las prácticas de autocontrol, legitimadas por los discursos modernos como naturales para el varón, son, en definitiva, prácticas orientadas hacia el gobierno del Otro-diferente (naturalizado). Asimismo, una vez mostrado que la pragmática del control naturaliza el ejercicio del poder en los varones, se hará evidente que el discurso de la superioridad masculina, aún fragmentado y desestructurado, perdura latente en el inconsciente cultural de las sociedades occidentales.

De este modo, en el punto segundo de este texto, expongo las matrices ideológicas desde las que se constituye la masculinidad hegemónica y examino su estado en las sociedades occidentales en relación con las estructuras sociales patriarcales; principalmente la división sexual del trabajo. En este mismo punto, me centro en el modelo hegemónico de masculinidad durante el inicio del capitalismo industrial, momento en que el éxito económico y el prestigio sociolaboral se constituyen en los pilares definitorios de la masculinidad en detrimento de la conducta antisocial y violenta. Estos dos modelos históricos de masculinidad se corresponden con dos de las creencias constitutivas de la masculinidad: la autosuficiencia triunfante del hombre moderno y la belicosidad heroica. La primera adquiere forma en la ficción de la construcción de sí mismo a partir del éxito sociolaboral y económico, mientras que la segunda, lejos de enajenarse de los nuevos modelos de masculinidad, perdura simbólica y prácticamente en la socialización de los varones en el deporte competitivo de equipo. En el punto tercero, desarrollo un análisis genealógico de la pragmática del control, mostrando cómo la creencia matriz de la autosuficiencia triunfante se vincula con la ideología de la supremacía masculina a partir de la identificación de la masculinidad con la racionalidad y el control de lo Otro naturalizado: el propio cuerpo, las mujeres y el mundo. Asimismo, expondré cómo, mientras que, originariamente, en la antigüedad clásica, las prácticas de autocontrol eran concebidas como una condición necesaria para el ejercicio del poder, posteriormente, durante la modernidad, serán naturalizadas como propias de los varones y normalizadas mediante la institucionalización de la ciencia moderna. Por otro lado, en este mismo punto, presento la crítica ecofeminista del varón dominador, pues desde sus análisis se observa que la instrumentalización de la naturaleza realizada 
por la cultura androcéntrica ha conllevado tanto las sociedades de dominación masculina como el modelo económico de explotación de la naturaleza. En el apartado cuarto, analizo las consecuencias que la pragmática del control tiene para la subjetividad masculina, concluyendo que, en la medida en que las prácticas de autocontrol están implícitamente dispuestas para ejercer el gobierno del Otro-diferente, la violencia, como dispositivo último dispuesto para este fin, es su reverso dialéctico. Finalmente, concluyo el texto con un somero análisis de los sentimientos de misoginia y homofobia latentes en el marco simbólico de socialización patriarcal de los varones y una breve síntesis de las ideas desarrolladas.

\section{La ideología de la supremacía masculina: el varón competi- tivo y autoritario}

Explica el psicoterapeuta y director del Centro de Estudios de la Condición Masculina de Madrid, Luís Bonino (2000), que la masculinidad hegemónica se sustenta en dos ideologías constitutivas: el individualismo moderno y la satanización/eliminación del Otro distinto.

El individualismo moderno conjuga el ideal clásico de la construcción de sí mismo con el concepto de "sujeto" de la antropología racionalista, generando, de este modo, la idea de un sujeto autosuficiente que se construye a sí mismo mediante el libre uso de la razón. Asimismo, como apunta Enrique Gil Calvo (1997), en los últimos siglos, a esta idea se le incorpora el valor protestante-capitalista de la eficacia, originando, de este modo, la creencia matriz de la autosuficiencia triunfante del hombre moderno.

La ideología de la satanización / eliminación del Otro diferente, originaria también de la antigüedad grecolatina, produjo el ideal del héroe guerrero, defensor de lo propio y conquistador de lo ajeno. Esta figura alberga en sí ciertas contradicciones, pues se encuentra siempre sujeta al código de honor patrio y a la subordinación jerárquica del ejército, pero experimenta de forma libre, valiente e individual el uso de la violencia. Bonino señala que en este ideal se originan dos creencias matrices de la masculinidad hegemónica: la de la belicosidad heroica y la del respeto a la jerarquía. 
Por último, Bonino expone que existe una cuarta creencia matriz de la masculinidad hegemónica: la ideología de la supremacía masculina sobre las mujeres. Esta ideología o creencia sostiene la idea de que los varones y las mujeres somos diferentes y desiguales por naturaleza. Según nuestras diferencias "naturales", los varones, sujetos libres y racionales, estaríamos capacitados para el trabajo productivo y la deliberación política, por lo que nos corresponde el monopolio de la esfera social pública; mientras que las mujeres, sujetos emocionales y dependientes, estarían esencialmente capacitadas para el trabajo reproductivo y de cuidado de los varones, por lo que les es propia la permanencia en la esfera social privada. Por lo tanto, la ideología de la supremacía masculina justifica la división sexual del trabajo y constituye un dispositivo de saber-poder que perpetúa la desigualdad social y política entre mujeres y varones. Pues, como señala Janet Saltzman (1992), en una sociedad cuya economía está estructurada en torno a la producción y al intercambio de plusvalía, el trabajo en el ámbito doméstico otorga pocas recompensas y escaso reconocimiento para las mujeres, lo que difícilmente las puede ofrecer la posibilidad de obtener poder respecto de sus análogos masculinos.

En la actualidad, la ideología de la supremacía masculina es considerada políticamente incorrecta por la opinión pública de las sociedades occidentales, donde, asimismo, la estricta división sexual de funciones se ha deteriorado. Durante el pasado siglo, el desarrollo de la sociedad de mercado deterioró la estricta división sexual de funciones con la apertura del mercado de trabajo para las mujeres y este hecho, conjuntamente con las reivindicaciones democráticas feministas del derecho a la igualdad, conllevó el reconocimiento legal del estatus de ciudadanía para las mismas (Marqués, 1991). Ahora bien, como explica Pierre Bourdieu (2005), en su obra La dominación masculina, el discurso ideológico falonarcisista y la cosmología androcéntrica siguen existiendo en estado parcial y como fragmentado tanto en nuestras estructuras cognitivas como en nuestras estructuras sociales. De este modo, nuestro inconsciente cultural estaría integrado por un sistema de oposiciones homólogas alto/bajo, arriba/abajo, delante/detrás, derecha/izquierda, recto/curvo, seco/húmedo, fuera (público) / dentro (privado), etc., que se corresponden con la oposición binaria masculino/femenino y que inducen la 
creencia de la supremacía masculina. Pero este sistema de esquemas de percepción (y acción) perdura no sólo como producto de una filogénesis social e histórica, sino porque se reproduce en las estructuras objetivas de nuestras sociedades, especialmente en la división del trabajo. "La mejor demostración de las incertidumbres del estatuto que se concede a las mujeres en el estado de trabajo es, sin duda, el hecho de que siempre están peor pagadas que los hombres, en igualdad de circunstancias, y que consiguen unos puestos menos elevados con títulos idénticos [...]" (2005, 115). En síntesis, "Los cambios visibles de las condiciones ocultan unas permanencias en las posiciones relativas." $(2005,113)$.

Curiosamente, siendo la evolución del capitalismo de estado hacia el capitalismo global de consumo el principal detonante del deterioro de la estricta división sexual del trabajo, su estadio previo, el nacimiento del capitalismo industrial, habría significado una radicalización tanto de ésta como de la diferenciación de roles en función del género-sexo. Elisabeth Badinter (1993) ha señalado que las condiciones del trabajo durante el capitalismo industrial exigían su realización fuera del ámbito del hogar durante toda la jornada laboral, una jornada laboral que generalmente ocupaba la mayor parte del día. Este hecho indujo a los varones, quienes ya tenían un mayor control de la esfera social pública, a desarrollar todo su trabajo en la misma, lo que conllevó que las exigencias del hogar y el cuidado y la educación de los hijos fueran desarrolladas totalmente por sus parejas, reforzándose así tanto la división sexual del trabajo como los roles sexuados en función del género. El posterior desarrollo tecnológico del hogar potenciaría aún más la división sexual de funciones, pues el hecho de que una única persona fuera capaz de organizar y desarrollar todo el trabajo doméstico, sujetaría en mayor grado a las mujeres a este ámbito y sus funciones (Clare, 2002).

En este momento, discursos de la más diversa índole van a destacar la contrariedad y la complementariedad de las características esencialmente masculinas respecto de las características esencialmente femeninas. La fuerza física, la templanza, la racionalidad, la disciplina, la firmeza, la independencia y la iniciativa constituían las actitudes caracteriológicas del varón prototípico. Por el contrario, la fragilidad, la debilidad, la vulnerabilidad, la emotividad, la impulsividad y la dependencia eran consideradas atribuciones propias de la femineidad. En suma, frente a la 
femineidad, la masculinidad representaba la fortaleza física y mental.

Probablemente, ambos estereotipos tienen un origen común, milenario en lo relativo a algunos de los atributos, en los mitos y creencias populares de la sociedad occidental. Pero, sin duda alguna, merece un comentario aparte el modo en que, a lo largo del siglo XIX, el discurso médico incorporó a su doctrina los prejuicios socioculturales sobre la femineidad, dotándolos en consecuencia, del carácter objetivo que a dicho discurso se le atribuye (Fraisse, 1991). Son muchos los modelos causales que explicaban la debilidad femenina, pero prácticamente todos se centraban en las funciones sexuales de la mujer; el hecho de tener una menstruación cada veintiocho días, de poseer ovarios o de poder quedar embarazada, hacía de la mujer un sujeto cuya racionalidad quedaba mermada por las vicisitudes de su "naturaleza". En consecuencia, la mujer era concebida como un ser vulnerable, emocionalmente inestable y fácilmente irritable (histérica), en suma, la debilidad encarnada. Y frente a este estereotipo, el modelo masculino aparecía como su contrario positivo. Es decir, el mero hecho biológico de ser varón significaba fortaleza física y mental.

¿Cuál es el origen de esta racionalización? ¿Qué razón mueve al colectivo científico a extremar y objetivar la imagen tradicional de la femineidad? El hecho de que la comunidad científica estuviera en su conjunto constituida por varones puede suponer un indicio en lo relativo a estas cuestiones. De hecho, esta racionalización de la femineidad y la masculinidad implicaba simultáneamente una justificación de y un instrumento para la división sexual del trabajo y el correlativo monopolio masculino de la esfera pública, quedando las mujeres confinadas en la esfera privada. En la construcción patriarcal de sexo-género, las mujeres no podían votar, formar parte de una investigación científica, dirigir una empresa o desempeñar función alguna de carácter intelectual. Estas actividades serían perniciosas tanto para su salud y sus "funciones propias", como para la sociedad, dada la imposibilidad de obtener un adecuado rendimiento. Consecuentemente, todas las funciones y privilegios de la esfera pública eran monopolizadas por los varones, quienes en función de su sexo se encontraban biológicamente capacitados para realizar dichas funciones. 
Véase cómo el conjunto de atributos masculinos citados anteriormente presupone otros dos atributos de segundo orden; competitividad y autoridad. La competitividad es el requisito fundamental para el trabajo en la vida pública; y la autoridad es un atributo propio de los dirigentes, del gobernador. Es necesario enfatizar el carácter de requisito, expectativa o demanda que posee el factor competitividad. Efectivamente, a todo varón se le supone a priori, en virtud de su sexo, un carácter competitivo. Pero, este carácter no es sólo una suposición sino también una exigencia (Marqués, 1991). Éste es el precio que todos los varones tienen que pagar por los privilegios de la esfera pública. Un "hombre" se define por lo que hace, no por lo que es. El varón se realiza en la vida pública, halla su identidad en su trabajo ${ }^{2}$. No es éste un coste bajo ${ }^{3}$. Pero en todo caso, este coste implica la posibilidad de mantener un estado de dominación o discriminación del colectivo masculino sobre el femenino, lo que a su vez, permite "disfrutar" las posibilidades de la vida pública y otorga a todo varón un espacio donde ejercer su competencia como gobernador: el hogar. Tal y como sucede con la competitividad, la autoridad es otro de los atributos que al varón se le suponen por el mero hecho de ser varón. Pero, en la vida pública no todos los varones son dirigentes, más bien la mayoría se encuentran subordinados tanto en su trabajo como en el orden político, mientras que sólo unos pocos desempeñan funciones directivas. Ahora bien, en las sociedades patriarcales, todos ellos se encuentran legitimados de facto por las estructuras sociales para ejercer su autoridad en el espacio de la intimidad, en el hogar, donde el varón se sitúa en la faceta del patriarca ${ }^{4}$ o cabeza de familia (Bourdieu, 2005). Por lo tanto, ni siquiera en el lugar que se les reserva, las mujeres disponen de completa iniciativa, su función específica y previamente determinada, consiste en crear un apacible refugio para el guerrero que retorna al hogar.

El historiador Peter Stearns (1990) ha señalado cómo el capitalismo industrial y su nueva y estricta división sexual de funciones conllevaron una redefinición de la masculinidad tradicional, en la que la fuerza física y el honor fueron reemplazados por el éxito, el dinero y el trabajo como fuentes de identificación y reconocimiento social para los varones. En un principio, la separación del padre del hogar habría deparado en un estadio de crisis para los varones. La ausencia de contacto directo entre el padre y 
sus hijos atentaba directamente contra el orden patriarcal, donde el padre organizaba y ejercía la educación de sus hijos. La radicalización de la división sexual de funciones confería a las madres nuevas tareas y "poderes" en el ámbito del hogar en lo que al cuidado y la educación de los hijos se refería. Este hecho conllevó un mayor distanciamiento, intransigencia e inaccesibilidad por parte de los padres, quienes, durante los escasos momentos que convivían en el hogar, ejercían una intensa acción disciplinaria (Badinter, 1993). Finalmente, el nuevo mito masculino del "varón sustentador de la casa" (breadwiner) y su estatus público acabaron justificando el alejamiento de los padres de los hogares y su nueva actitud disciplinaria.

Por otro lado, nos interesa destacar que si bien el nuevo modelo de masculinidad sustituyó valores añejos como la fuerza y el honor por el éxito económico y el estatus sociolaboral, los primeros no fueron enajenados de la masculinidad hegemónica, pues pervivieron en el inconsciente cultural masculino y son vehiculados en la socialización de los varones a través de la competición en los deportes colectivos (Elías y Dunning, 1992). A diferencia de la competitividad laboral, la competitividad en el deporte precisa de la agresión y la violencia como "valores" en torno al objetivo del éxito final. Además, en los deportes de equipo se posibilita la doble identificación de los varones como iguales en tanto que varones, es decir como sujetos de poder, y como desiguales jerarquizados en tanto que poseedores efectivos de poder. Dentro del equipo, los jóvenes varones se perciben $\mathrm{y}$ sienten iguales frente a los otros que se han de vencer, mientras que, a su vez, existe una jerarquía y un liderazgo que deben respetar para no fragmentar la solidez del grupo como tal. En esta jerarquía, la posición elevada y el respeto de los compañeros constituyen en última instancia un indicador de virilidad. De este modo, en la actualidad, la competición deportiva sustituye al ejército del estado-nación y a la prestación militar obligatoria en la socialización del varón moderno en una masculinidad jerárquica, competitiva y agresiva. 


\section{La definición de la masculinidad como autocontrol racional frente a la corporeidad natural: la pragmática del control}

La identidad masculina, en tanto que connatural a la esfera social pública y a su monopolio, precisa de un conjunto teóricopráctico formado simultáneamente por prácticas de control y autocontrol y por los discursos que tradicionalmente las han legitimado que he denominado "la pragmática del control" (Sambade, 2008). En mi opinión, la forma que "la pragmática del control" adquiere en el mundo moderno, como resultado de todos sus desarrollos históricos, constituye, junto con la ética del trabajo, el paradigma teórico-político desde donde se erige lo que Gil Calvo ha designado la creencia matriz de la autosuficiencia triunfante del hombre moderno.

Para sobrevivir en el competitivo mundo público, para poder sostenerse en el duro terreno de la vida laboral, artística, intelectual... y sobre todo, para ser un dirigente político, el varón precisa desarrollar al máximo una serie de estrategias y técnicas de control. Los orígenes de esta pragmática se remontan a los pilares de nuestra cultura occidental. Michel Foucault (1994) ha explicado cómo, en la filosofía clásica, las prácticas del cuidado de sí estaban encaminadas hacia el autogobierno, hacia el gobierno de los propios impulsos, como condición necesaria para el gobierno de los otros.

Para Foucault, el cuidado de sí habría constituido la forma pragmática con la que el mundo greco-romano problematizó éticamente la libertad cívica. En primer lugar, el concepto "el cuidado de uno mismo" (épiméleia/cura sui) hace referencia a un cierto modo de actuar o comportarse que se ejerce sobre uno mismo, a través del cual uno se hace cargo de sí transformándose o accediendo a un cierto modo de ser. Es decir, este concepto refiere a un conjunto de prácticas de construcción del sujeto.

¿Qué forma adquirió la preocupación por uno mismo en el mundo clásico? Foucault señala cómo el cuidado de sí encuentra su forma hegemónica en el "conócete a ti mismo" socrático (gnothi seaeutòn). Paradójicamente, el conocimiento que el sujeto debía adquirir para conocerse a sí mismo no venía dado por un saber centrado en uno mismo, sino por un saber que tiene como objeto las cosas, los hombres, el mundo y los dioses. Un saber por medio del cual el sujeto accede a la verdad. Este conocimiento 
estaba dotado simultáneamente de un carácter asertivo y de un carácter prescriptivo. Es decir, es un discurso en el que se dice simultáneamente lo que es verdadero y lo que se ha de hacer, un conocimiento que desvela la verdad y, a su vez, impone normas. Y en virtud de este carácter, es un discurso que produce y transforma el modo de ser del sujeto, el ethos del sujeto: es, por lo tanto, un discurso ethopoiético. A través del acceso a la verdad, el sujeto conoce lo que existe de divino en sí mismo y, conforme a esta realidad, habrá de ejercer su autogobierno.

Por lo tanto, la práctica de la libertad en la antigüedad clásica implicaba una transformación del ethos que lo dotase de una forma buena, bella, honorable... Pues, el ethos conlleva una serie de relaciones complejas con el otro y es, en sí mismo, perceptible a la mirada del otro. Desde esta perspectiva, el cuidado de uno mismo implica una preocupación ética que recae sobre el otro. Ahora bien, el cuidado del otro es secundario respecto del cuidado de uno mismo, es una consecuencia de este último, dado que la relación a uno mismo es ontológicamente primera. De este modo, el hombre (varón) libre que cuidaba de sí mismo se encontraba, por esta razón, en posición de conducirse debidamente en sus relaciones con los otros, de ocuparse de los otros. El hombre (varón) libre que cuidaba de sí sabría gobernar a su mujer, a sus hijos, su hogar, etc. Luego, la condición primera para el gobierno de los otros es el gobierno de uno mismo.

En la sociedad clásica, el buen gobierno, el gobierno justo, estaba delimitado inferiormente por la esclavitud y superiormente por la tiranía. La libertad se entiende como no-esclavitud, y en este sentido otorga una condición social: el esclavo, frente al hombre (varón) libre, no tiene ética. En el vértice opuesto nos encontramos con su recíproco inverso; el abuso de poder o la tiranía. En la tiranía, uno impone sus deseos y fantasías a los demás, desbordando así el ejercicio legítimo del poder. Pero, para los filósofos griegos, el tirano es en realidad un esclavo de sus apetitos. Por lo tanto, el buen soberano será aquel que, ejerciendo el poder, lo ejerce primeramente sobre sí mismo. Es más, precisamente el hecho de que este hombre (varón) se autogobierne es lo que le capacita para el gobierno de los otros. De este modo, el cuidado de sí constituye la condición ontológica, ética y pedagógica para llegar a ser un buen gobernante.

Foucault (1994) señaló cómo las prácticas del cuidado de sí se 
originan en un contexto donde se problematiza éticamente la libertad cívica en tanto que gobierno legítimo de los otros. Pero la estigmatización social de la esclavitud en la Gracia clásica pone de manifiesto que, desde una perspectiva democrática ilustrada, la legitimidad del gobierno del hombre (varón) libre griego sobre los otros estaría cuestionada de principio por la estructura social jerárquica y desigual en que se desarrolla.

En la modernidad, la pragmática masculina del control va a conllevar la comprensión del propio cuerpo y de la emotividad como mecanos que se deben controlar desde la mente en cuanto núcleo racional. Esta instrumentalización del propio cuerpo y de la emotividad halla su justificación en el paradigma epistemológico de la ciencia moderna y en la cosmovisión mecanicista de la realidad que le subyace. Con el desarrollo de la ciencia moderna, y más en concreto de las ciencias de la mente como la psicología o la psiquiatría, las prácticas de autocontrol no son ya concebidas como una condición política que los "ciudadanos" pueden desarrollar de acuerdo a la finalidad de la excelencia del gobierno, sino como leyes naturales (normas) que todo sujeto (masculino) debe desarrollar de acuerdo con su naturaleza humana (Foucault, 1994). Simultáneamente, de modo complementario, otros discursos desempeñaron la función de exclusión de las mujeres de la plenitud de la condición humana. Acabamos de ver, en este sentido, la legitimación de los prejuicios socioculturales que llevó a cabo el discurso médico del siglo XIX. Por otro lado, la dramática escisión dualista espíritu-cuerpo se intensifica con la cosmovisión mecanicista de la realidad, donde se explica todo lo real como producto de dos categorías ontológicas: la extensión y el movimiento; la materia y la causa $\mathrm{u}$ origen del movimiento. En este sentido, podemos observar cómo Descartes (1982), en sus Meditaciones metafísicas, sostiene que el alma y el cuerpo, el pensamiento y la extensión, son substancias independientes y autónomas. La prueba de su autonomía la encuentra Descartes en la certeza con que el entendimiento las percibe: con claridad y distinción a cada una por sí misma. Análogamente, define a las pasiones como aquellas percepciones o sentimientos que hay en nosotros y que afectan al alma sin tener su origen ella (sino en el cuerpo). Por lo que, la tarea del alma en relación con las pasiones consistirá en someterlas y ordenarlas conforme al dictamen de la razón (1963). 
En conclusión, la pragmática del control representa al varón como plenitud de la humanidad a partir de la posibilidad de control de la naturaleza; de la naturaleza interna mediante el control de sí mismo y de la naturaleza externa mediante el control del mundo y del resto de los seres naturales. Las mujeres en cuanto que seres determinados por las vicisitudes de su naturaleza serán, por ende, susceptibles de ser sometidas bajo la sujeción masculina. De este modo, el lema de la creencia de la autosuficiencia triunfante del hombre moderno, constrúyete a ti mismo y triunfa (Gil Calvo, 1997), se trasciende en el significado de "contrólate a ti mismo y obtén poder sobre la alteridad". Una vez aplicamos la hermenéutica del poder de género, parece indiscutible que el triunfo de los varones está indisociablemente ligado con el poder sobre el Otro-mujer y el Otro-naturaleza.

La crítica ecofeminista nos puede ayudar a comprender las implicaciones de la pragmática masculina de control, pues desde su epistemología se señala que los modelos hegemónicos de masculinidad han ocasionado tanto las sociedades de dominación masculina de las mujeres como el modelo económico de explotación de la naturaleza.

El ecofeminismo, al igual que el feminismo, es un movimiento social e intelectual múltiple y plural que alberga posiciones distintas e incluso contrarias en lo que a la crítica del patriarcado y del modelo de explotación de la naturaleza se refiere. Así, partiremos de la perspectiva que la pensadora australiana Val Plumwood (1993) desarrolla en su obra Feminism and the Mastery of Nature, donde intenta articular un ecofeminismo no esencialista para constituir un esquema teórico dirigido simultáneamente hacia la crítica de la dominación de los seres humanos y hacia la crítica de la dominación de la naturaleza (Puleo, 2000).

Val Plumwood caracteriza la cultura occidental por la preeminencia histórica de las siguientes premisas: 1) lo femenino y la mujer=la naturaleza; lo masculino y el hombre=la razón, la cultura; 2) inferioridad de la naturaleza y de la mujer; superioridad de la razón y del hombre; 3) naturaleza y mujer como opuestos a razón y humano; naturaleza como opuesto a cultura. Según Plumwood, esta lógica dualista se apoya en la conceptualización de la naturaleza como inerte, mecánica y pasiva, y en la identificación de la mujer con esta concepción de naturaleza. Y para superar esta lógica de dominación, debe asumirse que tanto 
los varones como las mujeres son parte integrante de la naturaleza y de la cultura. Así, Plumwood ejerce la crítica de la lógica del Dominio. Esta lógica encuentra sus raíces en la filosofía platónica, el cristianismo y el cartesianismo, y sostiene un profundo dualismo Naturaleza/Razón que implica el rechazo de aquello que se considera como mera naturaleza. Plumwood determina dos operadores fundamentales a través de los que la lógica del Dominio opera su colonización: 1) negar la dependencia con respecto a lo oprimido (sea la mujer o la naturaleza); y 2) negar que esa naturaleza sea un ser independiente y que tenga fines propios. $\mathrm{Su}$ finalidad es determinada exteriormente por el amo a partir de su definición instrumental. Por otro lado, Plumwood no propone un rechazo abierto de la razón, sino reemplazar su forma, históricamente estructurada mediante la lógica del Dominio, por otra más democrática, menos jerárquica y que incluya lo afectivo y lo corporal. Tal y como manifiesta la realidad de la crisis ecológica, la lógica de la dominación, con su instrumentalización colonizadora y su racionalidad economicista de explotación, se ha manifestado claramente irracional como estrategia ecológica de supervivencia.

Alicia Puleo (2000) valora positivamente la perspectiva de Val Plumwood, pues considera que integra la crítica de dos sesgos fundamentales de la manera en que se comprende a sí misma la especie humana: el androcentrismo y el antropocentrismo.

Puleo sostiene que el antropocentrismo y el androcentrismo se habrían ligado en su desarrollo histórico a partir de sus dualismos conceptuales constituyentes; Naturaleza/Cultura y Mujer/ Hombre. En primer lugar, define el androcentrismo como un sesgo patriarcal presente en la filosofía y las ciencias humanas que consiste en la confusión de lo masculino con lo propiamente humano o superior. Simultáneamente, el androcentrismo implica la concepción de lo femenino como la diferencia, la alteridad o el alejamiento respecto de la normalidad (masculina). A su vez, el antropocentrismo fuerte se define como el prejuicio según el cual sólo tiene valor lo propiamente humano. Este prejuicio se origina en el dualismo jerarquizado Naturaleza/Cultura y niega todo respeto moral a los seres no humanos. Pero el antropocentrismo tiene también implicaciones de género, pues a partir de la relación de identificación entre los conceptos de Naturaleza y Mujer se concibe a las mujeres como seres más próximos a la 
naturaleza que a la cultura, luego diferentes e inferiores respecto de los varones. Éstos últimos, entendidos como cultura, encarnan la plenitud de una humanidad que se concibe como sometimiento de todo el mundo natural y, dentro de éste, de las mujeres.

Alicia Puleo (2005) encuentra fundamental para el análisis de los sesgos androcéntrico y antropocéntrico de la cultura occidental, partir del hecho de que el concepto de Naturaleza se origina en una definición político-filosófica. La Naturaleza, concepto integrante del dualismo Naturaleza/Cultura, designa en el discurso filosófico occidental aquello que no tiene finalidad en sí mismo, lo que es un medio para un fin determinado desde su exterior $y$, en consecuencia, lo que puede ser apropiado como objeto por el hombre racional y productor. Asimismo, durante toda la historia de Occidente, este dualismo ha estado estrechamente ligado con el dualismo de género mujer/varón, naturalizando la diferenciación de roles sexuales, las identidades sexuadas y la desigualdad de estatus sociopolítico entre mujeres y varones.

La naturalización de la división sexual de funciones y su consiguiente perpetuación histórica han dado lugar al desarrollo de perspectivas morales y económicas diferentes entre mujeres y varones. Mientras que las mujeres se responsabilizan del cuidado de los seres próximos y centran sus cálculos económicos en la subsistencia del núcleo familiar, los varones priman el individualismo economicista y las leyes que amparen sus posibilidades en el competitivo mercado. La extensión generalizada de esta concepción economicista de la vida, mediante los procesos históricos de la colonización occidental y la implantación de una economía globalizada neoliberal, ha conllevado como consecuencias la destrucción ecológica a gran escala y la explotación de pueblos desfavorecidos.

Puleo hace hincapié en el hecho de que la ética instrumental economicista se corresponde con la identidad de varón dominador desarrollada en los patriarcados occidentales durante la modernidad. Y describe la autoimagen del varón dominador, en palabras de Cèlia Amorós, como un "sujeto inverosímil" o "desmadrado", una fantasía de sujeto "inengendrado y generador absoluto de sentido" (1997, 21-22). Esta identidad se constituiría fundamentalmente durante la adolescencia, etapa de ruptura de la dependencia afectiva respecto de la madre que el varón internalizará como negación y devaluación de todo lo que ella representa: 
suelo nutricio, cuidado, afectividad, apertura y compromiso hacia el otro. Y la identificación por oposición de la madre, lo femenino y la naturaleza, implica el distanciamiento afectivo y la instrumentalización de lo otro diferente como huellas propias del carácter masculino.

Según Puleo, a este imaginario le subyace una dinámica de género que exige la separación y el dominio de lo que se entiende como Naturaleza. La emoción, la benevolencia o la empatía son consideradas poco científicas, pasionales más que racionales, femeninas más que masculinas y, consecuentemente, son reprimidas como naturaleza inferior. Así, la represión de la propia naturaleza es medio y fin para el dominio de toda aquello que se concibe como Naturaleza. Pero cómo señala Puleo, la consecuencia de esta instrumentalización de la Naturaleza será la instrumentalización del propio anthropos dominador.

En definitiva, la crítica de la teoría ecofeminista a la idea de una masculinidad dominadora en tanto que ideología constituyente de las sociedades patriarcales y del modelo capitalista de explotación de la naturaleza, pone de manifiesto que el objetivo último de la pragmática del control, entendida como autocontrol, es la dominación de lo Otro diferente; lo Otro-naturaleza y lo Otromujer. Esta finalidad fue expresada abiertamente en la filosofía clásica, donde la pragmática del control constituye la condición necesaria para la adquisición de la excelencia política por parte del ciudadano libre en una sociedad estrictamente jerarquizada. Pero, con el paradigma epistemológico moderno, el nuevo concepto científico de universalidad generalizó las prácticas de autocontrol en el colectivo masculino como una característica natural de su identidad sexual. Asimismo, la cosmovisión mecanicista que instituyó la nueva ciencia radicalizó la auto-comprensión del propio cuerpo como un mecano, como materia articulada y dirigida por la mente o el alma, estableciendo así la mística del hombre-maquina. Durante el desarrollo del capitalismo industrial y junto con la ética del trabajo, esta pragmática habría generado en el imaginario masculino la idea de que el varón triunfa única y exclusivamente mediante su autoconstrucción. Pero, si bien las prácticas de autocontrol masculinas se encuentran dirigidas hacia la instrumentalización de lo Otro diferente, el coste de su eficacia será, como apunta Alicia Puleo, la instrumentalización 
del propio dominador. Las consecuencias de esta instrumentalización se pueden observar en la actual crisis ecológica, pero, de forma primigenia, se materializan en la subjetividad de los sujetos predestinados para el ejercicio de la dominación: los varones. Por lo tanto, la pragmática del control, fundamentada originariamente a partir del problema ético del gobierno justo, conllevará una represión de una parte importante de su potencialidad humana para los propios dominadores, al mismo tiempo que una objetivación e instrumentalización de las mujeres y de la naturaleza como objetivos de su control externo. Las sociedades de dominación masculina y el modelo economicista de explotación de la naturaleza son las consecuencias más flagrantes de esta problemática de género.

\section{La huella de la pragmática del control en la subjetividad masculina}

La pragmática del control hace que la subjetividad masculina se encuentre entreverada por una serie de estrategias de autocontrol cuyo objetivo final es el control y la dominación de aquello que se concibe como naturaleza, entre ello y fundamentalmente, de las mujeres. En su obra La masculinidad en crisis, Anthony Clare (2002) ha esquematizado un conjunto de características de la subjetividad masculina que a mi entender se podrían sistematizar como consecuencias de la socialización del varón moderno en la pragmática del control.

La primera de las consecuencias de la pragmática del control para la subjetividad masculina consiste en un hondo recelo de la intimidad y la afectividad y una fuerte disposición a la represión de la emotividad. Clare explica cómo, en efecto, el varón medio experimenta un profundo recelo a la hora de exteriorizar sus emociones. Oculta sus intenciones, miedos y sentimientos para expresar aquellas emociones que debería tener de acuerdo con las expectativas convencionales de la masculinidad. La consecuencia inmediata de esta materialización es una marcada superficialidad en el carácter del sujeto masculino medio.

Por ejemplo, todavía hoy, el varón medio manifiesta tremendas dificultades para organizar su vida personal; necesidades, prioridades, hábitos y rutinas. Su vida es el trabajo, y aquí ya está 
todo organizado; la empresa o el jefe se encargan de determinar un régimen interno de obligado cumplimiento. Por otro lado, su vida íntima suele quedar dispuesta para sus necesidades y comodidad a partir del trabajo en el hogar de su pareja sentimental, quien suele ejercerlo tanto si a su vez trabaja fuera del hogar como si no lo hace, encarnando así el mito de la superwoman (Molina Petit, 1993).

Pero sin duda, una de las materializaciones de la pragmática del control más represivas para el propio desarrollo del sujeto masculino se halla en las prácticas de autocontrol de la emotividad. Tal y como acabamos de afirmar, el varón medio experimenta un profundo recelo a la hora de exteriorizar sus emociones. Nos encontramos aquí con una vieja norma socializadora que todo varón debe cumplir conforme a su condición masculina: "Los chicos no lloran, tienen que ser fuertes". Al menos tan fuertes como se les supone.

Clare nos ofrece un ejemplo paradigmático al respecto. En Gran Bretaña la relación de mortalidad entre mujeres y varones a causa de cáncer de mama y de próstata respectivamente es de 1,4 a 1. Relación relativamente pequeña. En cambio, en 1998, el presupuesto para la investigación del cáncer de mama superó los cuatro millones de libras, mientras que el presupuesto del cáncer de próstata sólo obtuvo 137.000 libras. Este dato despertó diversas especulaciones. En particular, un antiguo diputado británico, Julian Critchley, atribuyó dicho desfase a la presión que el movimiento feminista ejercía sobre los consejos políticos, paradójicamente constituidos en un ochenta por ciento por varones. Pero lo cierto, es que este dato halla su significación en el reparo que los varones manifiestan a la hora de hablar acerca de sus dolencias íntimas y de la experiencia emocional de las mismas, lo que dificulta la detección de la enfermedad en sus fases iniciales.

El autocontrol masculino de la emotividad se origina en la definición de la masculinidad como fortaleza física y mental frente a la "connatural" debilidad femenina. El distanciamiento emocional tiene por objetivo el desmarque respecto de cualquier tipo de dependencia que pudiera debilitar al individuo en el sentido en que las mujeres son concebidas como personas débiles. Así, estas prácticas dan lugar al arquetipo del hombre duro, tal y como lo ha definido Badinter (1993): un varón que tiende a la huida, al aislamiento para no estar ligado a nada que pueda 
hacerle vulnerable. Pero, esta práctica de identificación por oposición constituye, en última instancia, una estrategia para el control emocional del otro más débil, particularmente, de las mujeres. Este hecho se puede corroborar en las múltiples y diversas tiranías emocionales que los agresores de mujeres manifiestan ante la desesperación y el daño emocional de sus víctimas, quienes en la mayor parte de las ocasiones suelen ser también sus parejas. El silencio, el descrédito, la ausencia de comunicación verbal, de atención, la minimización de los hechos..., son, entre otras, formas de maltrato emocional desarrolladas por los varones que ejercen violencia contra sus parejas (Hirigoyen, 1999).

Por lo tanto, la relación existente entre las prácticas masculinas de autocontrol emocional y la violencia psicológica contra las mujeres pone de manifiesto que el reverso dialéctico del autocontrol masculino es la violencia. Esta aseveración se puede observar en los actuales deportes competitivos en equipo, los cuales, tal y como sostiene Norbert Elías, se han convertido en un símbolo subliminal de la guerra al que trascienden sus valores. Nos encontramos aquí de nuevo con la creencia matriz de la belicosidad heroica, encarnada ahora por deportistas profesionales que se han convertido en ídolos mediáticos de millones de jóvenes en todo el mundo. Estos deportistas, varones en la mayor parte de los casos, constituyen el modelo de virilidad de los jóvenes varones que, mediante su imitación en los deportes correspondientes, son, parafraseando a Kate Millett (1975), preparados tanto social como psicológicamente en el ejercicio de la violencia. En XY. La identidad masculina, Elisabeth Badinter explica cómo los modernos deportes competitivos se corresponden con los ritos de iniciación en la virilidad que han tenido lugar a lo largo de toda la historia de la humanidad en todas las culturas conocidas tal y como asevera David Gilmore (1994). La virilidad se gana a término de combate, aguantando el dolor físico y exhibiendo las heridas. Este estoicismo moral y físico se adquiere actualmente en los deportes colectivos competitivos, donde los adolescentes varones pueden demostrar públicamente su desprecio por el dolor, el control de su cuerpo y su voluntad de ganar. No es de extrañar, en este sentido, que Alain Finkielkraut haya definido el cogito viril en los siguientes términos: "me expongo, así, pues, existo" (Cit. en Badinter, 1993, 120). Asimismo, la ideología de estos deportes no sólo sostiene que aguantar el dolor es un síntoma 
de valentía y virilidad, sino que el cuerpo es una herramienta, incluso una máquina o un arma, que se emplea para derribar a quienes se le opongan, los cuales son reducidos a la categoría de objetos. Badinter (1993) observa cómo la ideología del cuerpo máquina se ha plasmado en diferentes modelos de hipervirilidad como Rambo o Terminator, héroes de guerra representados por el cine estadounidense que constituyen los nuevos referentes de masculinidad para la socialización de los jóvenes varones. En definitiva, los modernos deportes colectivos socializan a los jóvenes varones tanto en el ejercicio de la violencia como en el autocontrol del dolor físico y de su expresión, valores masculinos que, por otro lado, siguen siendo representados paradigmáticamente por la prolífica producción estadounidense de cine bélico y sus personajes heroicos.

En íntima relación con las técnicas de autocontrol emocional aparece la problemática del suicidio de varones. Clare (2002) entiende que el suicidio tiene una naturaleza paradójica en relación con el autocontrol. Implica al mismo tiempo una declaración explícita de que la vida no se puede controlar y demostración de control definitivo. Una demostración de control definitivo propia del hombre duro como podemos observar en "la reflexión que hace L. Segal a propósito del suicidio de Mishina: Su furiosa búsqueda de la masculinidad... le provocó un deseo de purgarse de toda sensibilidad para poder convertirse en un objeto plenamente viril, en un hombre pleno -cosa que no era posible hasta el momento de su autodestrucción, el momento de la muerte" (Cit. en Badinter, 1993, 165). Pero, al mismo tiempo, una declaración explícita de que la vida no se puede controlar, pues, como señala Clare (2002), los varones que se suicidan se suelen encontrar en una terrible situación de abatimiento y desesperación que pocas veces se atreven a confesar. Un ejemplo extremo y cruel de esta conceptualización es el caso de los varones que se suicidan después de haber asesinado a su pareja sentimental. Efectivamente, estos varones se encuentran abatidos y desconcertados. Pero lo terrible de esta situación, es que su crisis se origina en la incapacidad de asumir que ya no pueden someter a su pareja (Sambade, 2008). Nos encontramos aquí con la identificación implícita del sometimiento de las mujeres con el autocontrol masculino, pues la liberación de este sometimiento por parte de la mujer en cuestión es lo que provoca el desconcierto del varón, su 
descontrol. Y la violencia contra ella es el acto encaminado hacia la recuperación del control. Ahora bien, en algún vestigio de su humanidad, el asesino debe de comprender que no ha recuperado su autoridad tras la muerte de su pareja, que sus prácticas no lograron el fin esperado. En este momento, el suicidio se presenta como la última y definitiva tentativa de control.

Clare (2002) entiende que la soledad de los varones que se suicidan arroja una cierta luz para la comprensión de la idiosincrasia de las relaciones sociales entre varones. Parece evidente que los varones nos relacionamos entre nosotros con una gran facilidad. Y, efectivamente, así es. Raramente se discrimina a un igual en tanto que integrante del colectivo masculino. Pero a la vez que fáciles, las relaciones entre los varones suelen ser superficiales. Por lo general, los varones manifiestan dificultad para establecer un vínculo íntimo y afectivo entre ellos mismos, puesto que, en sus relaciones, se comportan de acuerdo con las expectativas convencionales de la masculinidad. Clare observa cómo esto se corrobora en la denominada camaradería masculina; en las relaciones en los bares, en los clubes deportivos o en el trabajo, donde los varones comentan sus machadas; el número de coitos que han sido capaces de efectuar en una noche, el número de mujeres con las que se han acostado, la velocidad máxima a la que han conducido su vehículo o la borrachera más penosa que han experimentado, etc. Por otro lado, la superficialidad en el carácter del sujeto masculino medio y su dificultad para establecer relaciones íntimas con otros varones es también una consecuencia del miedo a la sospecha de la homosexualidad o de la homofobia en general. Pues, como señala Badinter (1993), la heterosexualidad deviene obligatoria en la masculinidad. Este hecho, de nuevo, nos permite constatar el carácter construido de la identidad colectiva masculina, dado que, como apuntara Michel Foucault (2005), es en el siglo XIX cuando el discurso médico definió y categorizó la homosexualidad como una desviación o una enfermedad respecto de la normalidad heterosexual. En el surgir de un sistema económico alimentado por la sexualización de los roles de trabajo, los comportamientos sexuales fueron transformados en identidades sexuales.

En todo caso, no parece que una masculinidad jerárquica, competitiva y agresiva sea proclive al establecimiento de relaciones íntimas entre varones. Vicent Marqués (1991) explica que, 
en sus relaciones, los varones compiten entorno a distintos objetivos, particularmente en torno al prestigio en el terreno laboral, pero que, en definitiva, los varones competimos para comprobar "quién es más hombre". De este modo, la sospecha acerca de la mayor virilidad del igual es una constante en el conjunto de relaciones sociales entre varones.

La sexualidad masculina representa otro ámbito de la experiencia vital del varón donde la pragmática del control deja una profunda y lastimosa huella (Bonino, 2000). Se puede considerar un caso paradigmático, ya que alberga tanto la cuestión del autocontrol como la del control del Otro-mujer, vía de la heterosexualidad obligatoria. La sexualidad es entendida desde la identidad masculina como una cuestión de control, pero no de control sobre el propio apetito sexual, que el varón considera imprevisible y caprichoso, sino sobre la funcionalidad eréctil del pene. El pene, símbolo del poder y la diferencia masculinas, constituye el instrumento que se ha de controlar (autocontrol) para ejercer el control definitivo sobre el Otro-mujer (Bourdieu, 2005). De este modo, la excitación de la mujer en cuestión, entendida como pérdida de control sobre sí misma, se atribuye a la capacidad instrumental del varón, sinónimo de su superioridad y poder fálico. Esta especie de narcisismo fálico tiene una serie de implicaciones negativas para la sexualidad de los varones. En primer lugar, implica la reducción de la sexualidad a genitalidad. Y en segundo lugar, la vivencia de la sexualidad como confirmación o demostración de la masculinidad, con la consiguiente reducción de las mujeres a terreno donde se desarrolla esta confirmación (Marqués, 1991).

El hecho de que la sexualidad sea una de las principales fuentes de identificación en lo relativo a la masculinidad conlleva una importante serie de frustraciones para los varones. Y no puede ser de otro modo, cuando la instrumentalización del pene te empuja a convertirte en una "máquina sexual", hiperpotente e hiperactiva, más vacía de emotividad y sensaciones. De nuevo, la sensación que en verdad está en juego no es otra que la sensación de poder. Así, Leonor Tiefer, especialista en trastornos de la masculinidad, asevera que más de la mitad de los varones que se quejan de una pérdida completa o parcial de su capacidad de erección, "van en busca de un pene perfecto" (Cit. en Badinter, 1993, 169). Análogamente, Vicent Marqués explica que la causa 
más frecuente de impotencia en los varones no es orgánica, sino psíquica; es la angustia provocada por la expectativa patriarcal de hipervirilidad. Pero la principal problemática de la sexualidad masculina no tiene a los propios varones como víctimas, sino a las mujeres, en las cuales, vía de la heterosexualidad obligatoria, se confirma la masculinidad. Este hecho, junto con la afectividad negativa hacia las mujeres que el sistema patriarcal induce a través de las imágenes míticas de la femineidad, constituye un estadio germinal de la violencia sexual contra las mujeres. La pornografía, con sus fantasías de violación, flagelación y dominación, encarna una manifestación explícita de esta tendencia. Y la casuística de agresiones sexuales contra las mujeres en el mundo occidental constata la realidad de esta lacra social.

Una primera conclusión deducible de lo hasta aquí expuesto es que la misoginia y la homofobia son dos sentimientos latentes en el arco ideológico que conforma la mística de la masculinidad y en la subsiguiente socialización de los varones en esta identidad colectiva. En su obra XY. La identidad masculina, Elisabeth Badinter defiende la tesis de que tanto la misoginia como la homofobia son el resultado de una masculinidad que se define por oposición a las mujeres y lo femenino. Esta oposición es especialmente frustrante para los varones porque lo femenino, aquello que la sociedad patriarcal ha definido como propio de las mujeres, es una potencia de la propia personalidad humana y, por ende, de la personalidad de cualquier sujeto varón. Los humanos somos bisexuales en este sentido. De hecho, Badinter considera que las "actitudes femeninas" no sólo son potencialidades que los varones evitan cultivar, sino conductas aprendidas en una primera etapa de femineidad, la crianza con la madre, que posteriormente se ven obligados a amputar, inhibir y reprimir en su proceso de identificación masculina. Es más, al tiempo que reprimen las conductas de género femenino (ser amado, comunicar emociones y sentimientos, ser pasivo...), se ven inducidos a desarrollar las contrarias entendidas como masculinas (amar, ser autocontrolado y activo...). Por lo tanto, para Badinter el varón que ensalza la masculinidad hegemónica es un hombre mutilado, fragmentado. Y la misoginia y la homofobia son las consecuencias de reprimir y frustrar sus deseos de expresión de e identificación con lo femenino. 
Comparto la idea de que los roles de sexo-género son potencialidades de todo ser humano, así como que unas actitudes son reprimidas y otras potenciadas en el proceso de socialización de género. Pero, a mi entender, el odio a las mujeres no se origina sólo en un deseo fetichista de identificación con lo reprimido, sino en el proceso previo de deshumanización e infravaloración de las personas que encarnan lo sometido. El odio a las mujeres se origina en el miedo fundado en compartir con ellas aquello por lo que justifico mi odio y dominación. El discurso médico del siglo XIX define a las mujeres como seres débiles y próximos a la naturaleza, el discurso filosófico de este mismo siglo como la trampa metafísica de la especie para la perpetuación del sufrimiento humano (Puleo, 1992), la tradición judeo-cristiana como el mal metafísico y moral (García Estébanez, 1992)... Discursos que justifican, todos ellos, la dominación masculina de las mujeres en base a sus supuestas no humanidad e inferioridad. Albert Memmi ha denunciado que las identidades del colonizador y del colonizado justifican la dominación mediante su naturalización (Memmi, 1971). Y en este sentido, la misoginia encardinada en el inconsciente masculino no es sino el fruto de toda una cultura histórica de dominación. El varón debe ser fuerte; luchar y rebelarse contra la toda dominación. Cooperar, rendirse, resignarse o someterse es cosa de débiles, de mujeres. Y así como el colonizador odia al colonizado por someterse, por no seguir luchando, en definitiva, por su debilidad, el varón odia a la mujer. Pero, en el fondo, este odio se origina en el miedo a ser identificado con lo sometido, a traspasar esa sutil línea definitoria que pone a unos de un lado y otras de otro. Ya que, como aseveró Hobbes (1989), dentro de la naturaleza humana, cualquiera puede someter a cualesquiera otros, todos tenemos la inteligencia necesaria para someter y para todos existe la posibilidad de ser sometidos. De este modo, en realidad, la lucha que el varón ejerce durante su proceso social de construcción, tiene como objetivo final la noidentificación con el oprimido.

Análogamente, la homofobia también halla sus raíces en el odio a lo femenino. En el lenguaje cotidiano, el homosexual no es la persona que tiene relaciones sexuales con otra persona de su mismo sexo, sino la "marica", "la loca", es decir, la encarnación de la femineidad en un varón (Badinter, 1993). Y un varón "femenino" representa la desviación de la norma, la anormalidad, 
incluso la enfermedad (Foucault, 2005), por lo que, como consecuencia, es marginado por la sociedad patriarcal, en general, y por sus homólogos varones, en particular. Esta norma se puede observar en la cotidiana y frecuente frase "eres una niña", con la que se socializa a los jóvenes varones en el odio hacia lo femenino mediante un acto de humillación y escarnio. Como consecuencia, el sentimiento homófobo es tan fuerte en el proceso patriarcal de socialización que muchos homosexuales lo experimentan primeramente en la forma de odio hacia sí mismos (Thompson, 2000).

En definitiva, la socialización masculina en la pragmática del control induce en los varones las prácticas de autocontrol de la emotividad y del cuerpo y el desprecio del dolor físico como rasgos de su identidad de género: la masculinidad. Pero el autocontrol masculino, en tanto que práctica de sí mismo, se encuentra implícitamente ligado con el control de las mujeres, definidas como seres inferiores y dependientes mediante la representación cultural de la femineidad que vehiculan socialmente los mass media. Con ello, se produce una asociación implícita entre el autocontrol de sí mismo y la sujeción de las mujeres, alimentada por el sentimiento de misoginia que trasciende a la idea de "masculinidad". Este hecho hace probable que cuando varones que han desarrollado una fuerte identificación con el modelo hegemónico de masculinidad se relacionen con mujeres independientes y emancipadas y no logren controlarlas, se produzca un sentimiento de frustración identitaria. Y el mecanismo históricamente dispuesto en la pragmática del control para su recuperación es la violencia represiva. Así, muchos varones experimentan crisis identitarias cuando sus parejas deciden finalizar su relación sentimental. Y, en la medida en que la sujeción de sus parejas se traduce en un sentimiento de control sobre sí mismos, se verán inducidos por su socialización de género a ejercer violencia contra ellas como medio confirmar su masculinidad y recuperar su autoestima. Concluyendo, la definición de una masculinidad autocontrolada, independiente, no emotiva, agresiva, y heterosexual, como norma, se erige sobre un discurso de infravaloración de las mujeres, sobre un marco de violencia simbólica, que incubada en los sentimientos de misoginia y homofobia, y proyectada sobre sí mismos durante el proceso patriarcal de socialización, incitará a los varones a situar a las mujeres y los gays en el punto de mira de sus prácticas violentas. 
1 Miembro de la Cátedra de Estudios de Género de la Universidad de Valladolid.

2 Richard Sennett explica en su obra La corrosión del carácter que la "ética del trabajo" o el ascetismo mundano, tal y como la denominó Max Weber primeramente, posibilitó conjuntamente con el modelo keynesiano-fordista de producción y las garantías sociales del estado del bienestar, la construcción de un ethos del trabajo. Es decir, la posibilidad de obtener una identidad estable a partir de un trabajo que permitía constituir un proyecto de vida a largo plazo. A esta reflexión habría que añadirle que esa posibilidad tuvo lugar generalmente para los trabajadores asalariados varones, en la medida en que éstos constituían la fuerza productiva en su mayor parte. Sennett, Richard. La corrosión del carácter: las consecuencias personales del trabajo en el nuevo capitalismo, Barcelona: Anagrama, 2000.

3 Anthony Clare asevera que durante la jubilación los varones experimentan una crisis existencial relacionada, precisamente, con la pérdida de su rol laboral, rol que constituye un elemento fundamental de la identidad de los varones. En este mismo sentido, indica como el porcentaje más elevado de suicidios se produce en este periodo de la vida del varón. Clare, Anthony. La masculinidad en crisis, Trad. Irene Cifuentes, Madrid: Taurus, 2002.

4 Recordemos que Cèlia Amorós nos ofrece, entre otras, la siguiente descripción del patriarcado: "el patriarcado es así un sistema de implantación de espacios cada vez más amplios de iguales en cuanto cabezas de familia, es decir, en cuanto que controlan en conjunto a las mujeres, a la vez que de desiguales jerarquizados en tanto que, para ejercer tal control, dependen los unos de los otros". Asimismo, explica que los varones admiten su subordinación porque a partir del pacto patriarcal entre varones y de las prácticas de reconocimiento-terror, si bien no todo varón detenta posiciones de poder, a todo varón se le reconoce como posible candidato al poder en tanto que miembro del colectivo que ejerce el poder, lo que genera la ilusión de que en un momento futuro les llegará su turno, de que pueden poder. "Para una teoría nominalista del patriarcado". Amorós, Cèlia. La gran diferencia y sus pequeñas consecuencias... para las luchas de las mujeres, Madrid: Cátedra, 2005, 111-136, Pág. 114.

\section{Bibliografía}

Amorós, Cèlia. Tiempo de feminismo. Sobre feminismo, proyecto ilustrado y postmodernidad. Madrid: Cátedra, 1997.

Badinter, E., XY. La identidad masculina. Trad. Monserrat Casals, Madrid: Alianza Editorial, 1993.

Bonino, Luís. "Varones, Género y Salud mental: deconstruyendo la "normalidad" masculina". En: Segarra, Marta y Àngels Carabí (eds.). Nuevas Masculinidades. Barcelona: Icaria, 2000, 41-64.

Bourdieu, Pierre. La dominación masculina. Trad. Joaquín Jordá, Barcelona: Anagrama, 2005. 
Clare, Anthony. La masculinidad en crisis. Trad. Irene Cifuentes, Madrid: Taurus, 2002.

Descartes, René. Las pasiones del alma. Trad. Consuelo Berges, Buenos Aires: Aguilar, 1963.

------. Discurso del método; Meditaciones metafísicas. Trad. Manuel G. Llorente, México: Espasa-Calpe, 1982.

Elías, N. y E Dunning. Deporte y ocio en el proceso de la civilización. Madrid: F.C.E., 1992.

Foucault, Michel. Hermenéutica del Sujeto. Trad. Fernando Álvarez Uría, Madrid: La Piqueta, 1994.

------. Historia de la sexualidad. Tomo I. La voluntad de saber. Trad. Julia Varela y Fernando

Álvarez Uría, Madrid: Siglo XXI, 2005.

Fraisse, Geneviève. Musa de la razón. La democracia excluyente y la diferencia de los sexos. Trad. Alicia Puleo, Madrid: Cátedra, 1991.

García Estébanez, Emilio. ¿Es cristiano ser mujer?. Madrid: Siglo XXI, 1992.

Gil Calvo, Enrique. El nuevo sexo débil. Madrid: Temas de hoy, 1997.

Gilmore, David D. Hacerse hombre: concepciones culturales de la masculinidad. Barcelona: Paidós, 1994.

Hirigoyen, Marie France. El acoso moral: el maltrato psicológico en la vida cotidiana. Barcelona: Piados, 1999.

Hobbes, Thomas. Leviatán. La materia, forma y poder de un Estado eclesiástico y civil. Trad. Carlos Mellizo, Madrid: Alianza, 1989.

Marques, Josép Vicent y Raquel Osborne. Sexualidad y sexismo. Madrid: UNED, Fundación Universidad-Empresa, 1991.

Memmi, Albert. Retrato del colonizado; precedido por el retrato del colonizador. Madrid: Cuadernos para el diálogo, 1971.

Millett, Kate. Política sexual. Trad. Ana María Bravo García, Madrid: Cátedra, 1975.

Molina Petit, Cristina. Dialéctica feminista de la ilustración. Barcelona: Anthropos, 1993.

Plumwood, Val. Feminism and the Mastery of Nature. London and New York: Routledge, 1993.

Puleo, Alicia H. Dialéctica de la sexualidad. Género y sexo en la filosofía contemporánea. Madrid: Cátedra, 1992.

------. "Ecofeminismo: hacia una redefinición filosófico-política de "naturaleza" y "ser humano"", en Amorós, Cèlia. Feminismo y filosofía. Madrid: Síntesis, 2000, 165-190.

------. "Los dualismos opresivos y la educación ambiental", Isegoría/32, 2005, 201-214.

Saltzman, Janet. Equidad y género. Una teoría integrada de estabilidad y cambio. Trad. María Coy, Madrid: Cátedra, 1992.

Sambade, Iván. "Medios de comunicación, democracia y subjetividad masculina". En: Puleo, Alicia H. (coord.). El reto de la igualdad de género. Madrid: Biblioteca Nueva, 2008, 344-360.

Stearns, Peter N. Be a man! Males in modern society. $2^{\text {a }}$ ed., Nueva York: Holmes \& Meier, 1990.

Thompson, Cooper (2000). "Debemos rechazar la masculinidad tradicional". En Thompson, Keith. Ser Hombre, Barcelona: Kairós. 